\title{
The synthesis of palladacyclopentadienyl derivatives from rigid bis-alkynes and their use as precursors in the synthesis of fluoroanthene-like cycles under mild conditions. A reactivity investigation
}

\author{
Luciano Canovese ${ }^{\mathrm{a}, *}$, Fabiano Visentin ${ }^{\mathrm{a}}$, Gavino Chessa ${ }^{\mathrm{a}}$, Paolo Uguagliati ${ }^{\mathrm{a}}$, \\ Claudio Santo ${ }^{\text {a }}$, Lucia Maini ${ }^{\mathrm{b}}$ \\ a Dipartimento di Chimica, Università Ca' Foscari, Calle Larga S. Marta 2137, 30123 Venezia, Italy \\ b Dipartimento di Chimica "G. Ciamician", via Selmi 2, 40126 Bologna, Italy
}

Received 28 November 2006; received in revised form 18 January 2007; accepted 18 January 2007

Available online 31 January 2007

\begin{abstract}
The palladium $(0)$ derivatives of the type $\left[\operatorname{Pd}\left(\eta^{2}-\mathrm{ol}\right)\left(\mathrm{LL}^{\prime}\right)\right](\mathbf{2})(\mathrm{ol}=\mathrm{dmfu}$ : dimethylfumarate $(\mathbf{a})$, fn: fumaronitrile $(\mathbf{b})$, tmetc: tetramethylethylenetetracarboxylate (c), LL' = HNSPh: 2-(phenylthiomethyl)-pyridine (A), BiPy: 2,2'-bipyridyl (B), DPPE: bis-diphenylphosphinoethane (C)) were reacted in $\mathrm{CH}_{2} \mathrm{Cl}_{2}$ with 1,8-bis(methylpropynoate)naphthalene (1) and 2,2'-bis(methylpropynoate)biphenyl (1'). At variance with the flexible $\mathbf{1}^{\prime}$ derivative, the rigid bis-alkyne $\mathbf{1}$ reacts smoothly to give the corresponding cyclopalladate complexes $\left[\mathrm{PdC}_{4}(\mathrm{COOMe})_{2}(\mathrm{Ph})_{2}\left(\mathrm{LL}^{\prime}\right)\right](3)$. The rates of reaction were determined and the X-ray diffraction structure of the complex $\left[\mathrm{PdC} \mathrm{C}_{4}(\mathrm{COO}-\right.$ $\left.\mathrm{Me})_{2}(\mathrm{Ph})_{2}(\mathrm{HNSPh})\right](\mathbf{3 A})$ is reported. The reactivity of the complexes $\left[\mathrm{PdC}_{4}(\mathrm{COOMe})_{2}(\mathrm{Ph})_{2}\left(\mathrm{LL}^{\prime}\right)\right]\left(\mathrm{LL}^{\prime}=\mathrm{HNSPh}(\mathbf{3 A}), \mathrm{BiPy}(\mathbf{3 B})\right.$, DPPE (3C)) was studied by reacting these complexes with $\mathrm{fn}$ and tetracyanoethylene (tcne), respectively. The ensuing fluoroanthene-like compounds were fully characterized.
\end{abstract}

(C) 2007 Elsevier B.V. All rights reserved.

Keywords: Palladium complexes; Olefin insertion; Palladacyclopentadienyl complexes

The reactions of unsaturated molecules catalyzed by palladium complexes represent an important topic in organometallic chemistry and consequently a wealth of papers have been recently published in this interesting field [1]. Moreover, exhaustive investigations on the attack of some dissymmetrically and symmetrically substituted alkynes on palladium $(0)$ olefin derivatives to give the corresponding palladacyclopentadienyl complexes were recently carried out by Elsevier's group [2] and in our laboratory .In the latter case, the related mechanism was proposed on the basis of structural and kinetic evidence [3].

In particular, the alkynes used had the general structure $\mathrm{ZC} \equiv \mathrm{CZ}(\mathrm{Z}=\mathrm{COOMe}, \mathrm{COOEt}, \mathrm{COO} t-\mathrm{Bu})$ and their

\footnotetext{
${ }^{*}$ Corresponding author. Tel.: +39 041 2348571; fax: +39041 2348517.

E-mail address: cano@unive.it (L. Canovese).
}

reactivity was found to be strongly related to their steric hindrance as can be expected in the case of an associative alkyne attack. Thus, we decided to decrease the molecular degrees of freedom by linking together two alkyne groups in hopes that this approach could represent a further step toward the synthesis of novel cyclopalladate compounds which might eventually collapse into new condensed polycyclic compounds. We have therefore synthesized the diynes 1,8-bis(methylpropynoate)naphthalene $\mathbf{1}$ and 2,2'bis(methylpropynoate)biphenyl $\mathbf{1}^{\prime}$ and studied their reactivity toward olefin palladium( 0 ) derivatives $\mathbf{2}$ to give the corresponding palladacyclopentadienyl complexes $\mathbf{3}$ (Chart 1).

The electron-deficiency of the alkyne - a prerequisite for the quantitative oxidative coupling toward palladium $(0)$ olefin complexes - is obtained, in the case of the bis-alkyne 


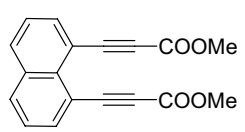

1<smiles>[O][Pb]1[Al]CC[Te]1</smiles>

2

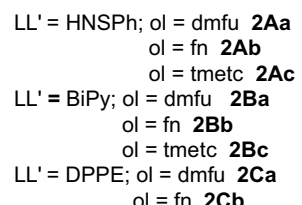

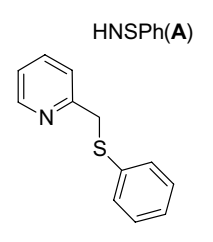
$\operatorname{BiPy}(\mathbf{B})$<smiles>c1ccc(-c2ccccn2)nc1</smiles>
$\operatorname{DPPE}(\mathbf{C})$

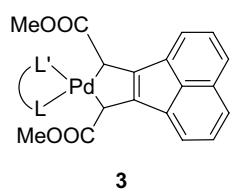

$L L^{\prime}=$ HNSPh $3 A$ $\mathrm{LL}^{\prime}=\mathrm{BiPy} \quad 3 \mathrm{~B}$ $L^{\prime}=$ DPPE $3 C$

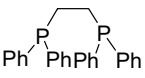

$\mathrm{dmfu}=$ dimethylfumarate $(\mathbf{a})$ $\mathrm{fn}=$ fumaronitrile $(\mathbf{b})$ tmetc $=$ tetramethy lethylenetetracarboxy late (c)

Chart 1.

1, through the presence of two electron withdrawing ester groups coupled with the extended delocalized naphthalene $\pi$-system. On the other hand, the bis-alkyne $\mathbf{1}^{\prime}$ reacts only with the most efficient palladium $(0)$ complexes $\left[\operatorname{Pd}\left(\eta^{2}-\right.\right.$ $\mathrm{dmfu})(\mathrm{BiPy})]$ (2Ba) and $\left[\mathrm{Pd}\left(\eta^{2}-\mathrm{dmfu}\right)(\mathrm{HNSPh})\right]$ (2Aa), yielding however several uncharacterized by-products in both the reaction mixtures. Apparently, the spatial disposition of the unsaturated triple bond is also important and the two alkyne moieties forced in the same plane might give further information on the mechanism of attack while reducing the possibility of formation of bridged complexes and other by-products.

We have therefore studied the reaction reported in Scheme 1 and the results are summarized in Table 1.

As can be seen in Table 1 the reaction rate is heavily influenced by the nature of the ancillary ligand and of the olefin. As a matter of fact the complex 2Aa is the most reactive substrate since $\mathrm{dmfu}$ is the olefin less firmly bound

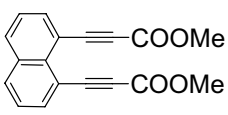

$+$

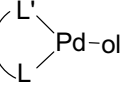

2

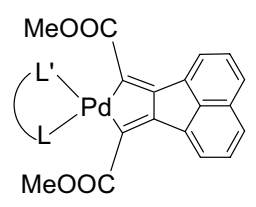

3
Table 1

Reaction time and conversion ratio for the reaction between the complexes $\left[\operatorname{Pd}\left(\eta^{2}-\mathrm{ol}\right)\left(\mathrm{L}-\mathrm{L}^{\prime}\right)\right]\left(2 \times 10^{-2} \mathrm{~mol} \mathrm{dm}{ }^{-3}\right)$ and diyne $\mathbf{1}\left(3 \times 10^{-2} \mathrm{~mol} \mathrm{dm}^{-3}\right)$ followed by NMR technique at $25^{\circ} \mathrm{C}$ in $\mathrm{CDCl}_{3}$

\begin{tabular}{lrrrrrrrr}
\hline Complex & $\mathbf{2 A a}$ & $\mathbf{2 A b}$ & $\mathbf{2 A c}^{\mathrm{a}}$ & $\mathbf{2 B a}$ & $\mathbf{2 B b}$ & $\mathbf{2 B c}^{\mathrm{a}}$ & $\mathbf{2 C a}$ & $\mathbf{2 C b}$ \\
\hline Conversion (\%) & 100 & 100 & 100 & 100 & 100 & 5 & 95 & 5 \\
Reaction time & $<5^{\prime}$ & $<5^{\prime}$ & $24 \mathrm{~h}$ & $<5^{\prime}$ & $60^{\prime}$ & $48 \mathrm{~h}$ & $48 \mathrm{~h}$ & $48 \mathrm{~h}$ \\
\hline
\end{tabular}

${ }^{\text {a }}$ Values determined from the second order rate constant (see text).

to the palladium $(0)$ centre [4] and the species $\mathrm{HNSPh}$ belongs to the pyridylthioether ligand family which imparts a remarkable reactivity to its complexes [3a,3c]. In this respect, the $\mathrm{HNSPh}$ derivatives are unable to differentiate among leaving olefins. At variance, the importance of the olefin is well documented by complexes $\mathbf{2 B}$ in which the strength of the $\mathrm{Pd}$-olefin bond is clearly borne out by the comparison between substrates $\mathbf{2 B a}$ and $\mathbf{2 B b}$ : the fn derivative is far less reactive, albeit sterically favoured, due to the relative strength of the Pd-dmfu vs. Pd-fn bonds [4]. The tmetc derivatives are important since they belong to the most widely studied $\operatorname{Pd}(0)$ substrates and in this respect they provide a useful comparison test $[4,5]$. As a matter of fact, the steric hindrance of tmetc makes achievable a variety of reaction rates that would otherwise be too high to be conveniently studied by usual techniques. The 2Cc derivative is almost unreactive (only a partial decomposition is noticed after several days) while complexes $\mathbf{2 A c}$ and $\mathbf{2 B c}$ were studied in detail and the data in Table 1 are better described by the $k_{2}$ values which are $(2.25 \pm 0.05) \times 10^{-3}$ and $(1.77 \pm 0.05) \times 10^{-5} \mathrm{~mol}^{-1} \mathrm{dm}^{3} \mathrm{~s}^{-1}$, respectively [6]. In Fig. 1 plots of the concentration changes for the complexes 2Aa and 3A determined by NMR technique and the related non-linear fit are reported.

The direct comparison of the ensuing $k_{2}$ with the $k_{2}$ value determined for the same complex $2 \mathrm{Aa}$ when reacting with $\mathrm{DMA}^{[3 \mathrm{a}]}\left(k_{2}=0.137 \mathrm{~mol}^{-1} \mathrm{dm}^{3} \mathrm{~s}^{-1}\right.$; DMA $=$ dimethylacetylenedicarboxylate) shows that the diyne $\mathbf{1}$ is consid-

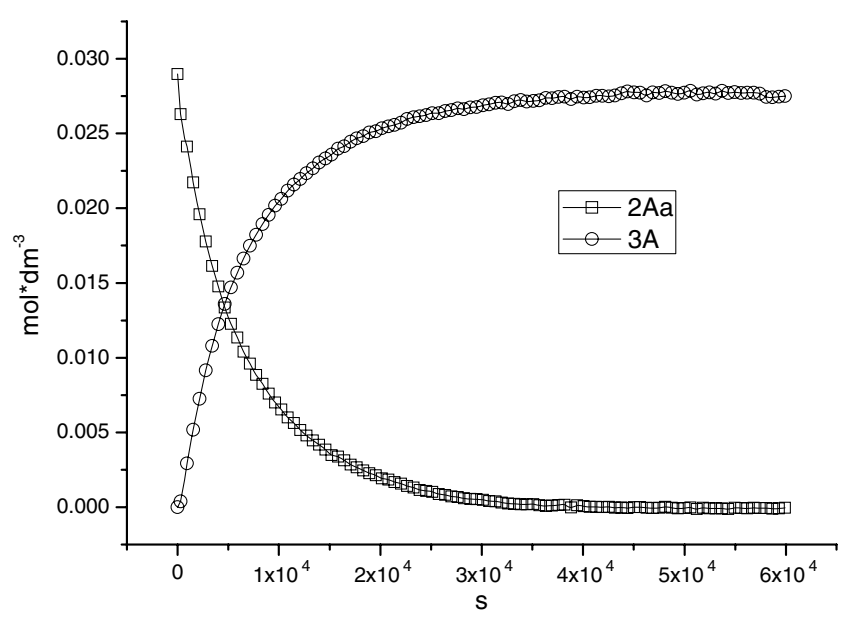

Fig. 1. Concentration profiles determined by ${ }^{1} \mathrm{H} \mathrm{NMR}$ in $\mathrm{CDCl}_{3}$ at $298 \mathrm{~K}$ and related best fit for the reaction between the complex $\mathbf{2 A a}$ and $\mathbf{1}$ to give complex 3A. 
erably less reactive since it is disfavoured by both steric (rigid system) and electronic factors (naphthalene is less effective than the ester group in withdrawing electrons). The structure of 3A substrate was determined by X-ray diffraction and the ORTEP representation is reported in Fig. 2.

The complex crystallizes with one water molecule which does not interact with the organometallic molecule but forms a hydrogen bond with another water molecule $(\mathrm{O} \cdots \mathrm{O} 2.900(5) \AA)$. The palladium(0) has a planar geometry, two coordination sites being occupied by the bidentate ligand 2-((phenylthio)methyl)pyridine, and the other two by the carbons of the cyclopalladate moiety. The $\mathrm{Pd}_{1-}$ $\mathrm{S}_{1}$ and $\mathrm{Pd}_{1}-\mathrm{N}_{1}$ bond lengths are very close to those determined in the case of related pyridylthioether and quinolylthioether complexes [3a,c] while the $\mathrm{Pd}_{1}-\mathrm{C}_{2}$ and $\mathrm{Pd}_{1}-\mathrm{C}_{15}$ distances lie within those of the pyridylthioether $(2.013,2.042 \AA)$ and those of the quinolylthioether derivatives $(2.056,2.064 \AA$ ) $)$.

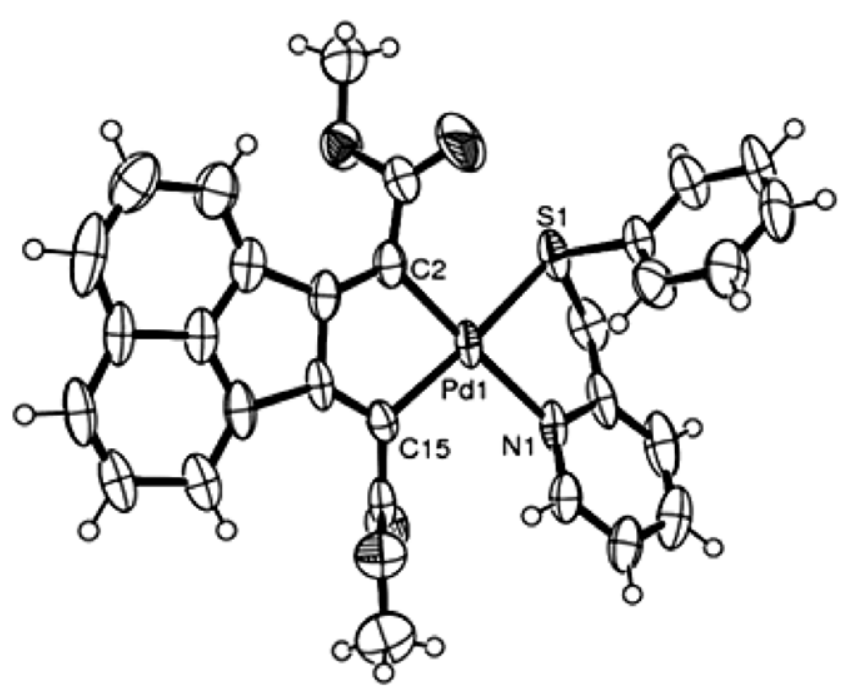

Fig. 2. The X-ray diffraction structure of the complex 3A. Selected bond distances (A): $\mathrm{Pd}_{1}-\mathrm{C}_{2} 2.027(8), \mathrm{Pd}_{1}-\mathrm{C}_{15}$ 2.060(7), $\mathrm{Pd}_{1}-\mathrm{N}_{1}$ 2.134(7), $\mathrm{Pd}_{1}-\mathrm{S}_{1}$ 2.364(2).
An important feature of complexes $\mathbf{3}$ is represented by their reactivity toward electron-poor olefins to give fluoranthene-like macrocycles under very mild conditions. On the contrary, it is well known that the synthesis of fluoranthene-like compounds proceeds via a Diels-Alder condensation process between a diene and a dienophile performed at high temperature and using the dienophile itself as the solvent [7].

Catalyzed production of cycles and in general of polysubstituted benzene derivatives has been recently reviewed [8] and a number of compounds have been obtained by condensation of alkynes under relatively mild conditions. Itoh and co-workers were able to produce cycles in good yield by taking advantage of the palladium catalyzed reactions between flexible diynes and DMA [9] or of thermal decomposition of the $\operatorname{Pd}(0)$ triyne complex or of the $\mathrm{Pd}_{2}(\mathrm{DBA})_{3}$ catalyzed reaction of dimethyl 4,9-dioxatrideca-2,7,12-triyne-1,13-dioate [10]. Rigid diynes were instead used by Costa and co-workers [11] in cobalt catalyzed reactions to give mixtures of well characterized polycondensed cycles. However, at the best of our knowledge no other attempts at condensing similar rigid diynes with palladium complexes were carried out. Therefore, we tried to form the polycyclic species by reacting the substrates 3 with fumaronitrile and tetracyanoethylene, thereby obtaining the fluoranthene derivatives $\mathbf{4}$ and $\mathbf{5}$ respectively, according to Scheme 2.

The mechanism of the reaction in Scheme 2 carried out in chlorinated solvents at RT presumably involves a preliminary coordination of the electron-poor olefin on the flat palladium(II) centre followed by a Diels-Alder type condensation between the olefin and the coordinate diene. The subsequent displacement of the fluoranthene-like cycle is promoted by the stabilization of the ensuing $\operatorname{Pd}(0)$ derivative by the olefin in excess. In this respect, the difference among the rates of reaction (1) and (2) as reported in Table 2 reflects the efficiency of tcne when compared with fn as a dienophile, the yields and the rates being independent of the nature of the ancillary ligand, indicating that the electronic factors overwhelm the steric ones.
(1)

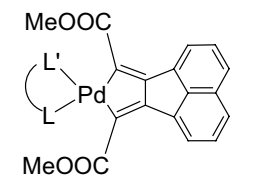

3

(2)

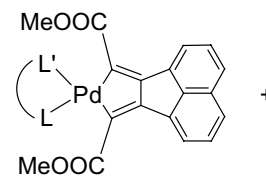

3

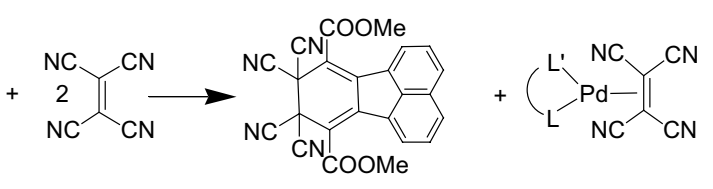

5

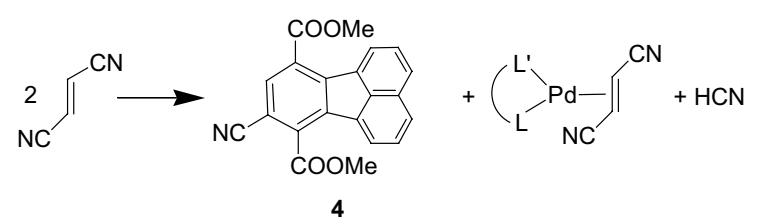

Scheme 2. 
Table 2

Reaction time and conversion ratio for the reaction between the complexes $3\left(2 \times 10^{-2} \mathrm{~mol} \mathrm{dm}^{-3}\right)$ and olefin $\left(6 \times 10^{-2} \mathrm{~mol} \mathrm{dm}^{-3}\right)$ followed by NMR at $25^{\circ} \mathrm{C}$ in $\mathrm{CDCl}_{3}$

\begin{tabular}{lllllll}
\hline Complex & 3A & & 3B & & $3 \mathbf{3}$ & \\
\hline Reacting olefin & fn & tcne & fn & tcne & fn & tcne \\
Conversion (\%) & $52^{\text {a }}$ & 91 & 82 & 93 & 89 & 87 \\
Reaction time (h) & 60 & 1 & 60 & 1 & 60 & 1 \\
\hline
\end{tabular}

a The reaction between $\mathbf{3 A}$ and fumaronitrile yields the compound $\mathbf{4}$ and a mixture of unidentified compounds.

Reaction (2) involves slow formation of a bis-nitrile dienyl intermediate which undergoes fast aromatization by dehydrocyanation to give dimethyl 8-cyanofluoranthene7,10-dicarboxylate 4 . This fact deserves a further comment since the formation of fluoranthene cycle proceeds in the absence of a strong base, in contrast with other findings [12]. Apparently, the driving force of the reaction arises from the synergic interplay of the aromatization process yielding the cycle and the stabilization of the palladium(0) derivative induced by an efficient electron withdrawing olefin.

We also endeavoured to investigate the possibility of the catalytic production of the fluoranthene cycle, but we obtained no significant results. The reaction of complex $\mathbf{3}$ with tcne leads to the formation of the dimethyl-8,8,9,9-tetracyano-8,9-dihydrofluoranthene-7,10-dicarboxylate $\mathbf{5}$, thereby confirming the proposed mechanism, but also to the formation of the very stable $\left[\operatorname{Pd}\left(\eta^{2}\right.\right.$-tcne $\left.)\left(L-L^{\prime}\right)\right]$ derivative which prevents any catalytic process.

The reaction under catalytic conditions of complexes 3A-3C with fn leads to a slight stoichiometric excess of the dimethyl-8-cyanofluoranthene-7,10-dicarboxylate $(\mathrm{TON} \leqslant 3)$ but, in this case the presence in solution of hydrocyanic acid could trigger the formation of inert cyano species even in the presence of the base $\mathrm{NEt}_{3}$.

We are now involved in a supplementary study exploring the temperatures, solvents and alkenes that will allow an efficient catalytic process in the production of similar fluoranthenyl derivatives.

\section{Appendix A. Supplementary material}

X-ray crystallographic data in CIF format, crystal data and structure refinement. Details on the synthesis and characterization of the novel chemical derivatives. Supplementary data associated with this article can be found, in the online version, at doi:10.1016/j.jorganchem.2007.01.046.

\section{References}

[1] (a) N.E. Schore, Chem. Rev. 88 (1988) 1081;

(b) H. Tom Dieck, C. Munz, C. Mueller, J. Organomet. Chem. 19 (2000) 2403;

(c) S. Cacchi, J. Organomet. Chem. 576 (1999) 42; (d) M. Rubin, A.W. Sromek, V. Gevorgyan, Synlett. 15 (2003) 2265; (e) R. van Belzen, H. Hoffman, C.J. Elsevier, Angew. Chem., Int. Ed. Eng. 36 (1997) 1743;

(f) R. van Belzen, R.A. Klein, H. Kooijman, N. Veldman, A.L. Spek, C.J. Elsevier, Organometallics 17 (1998) 1812;

(g) R. van Belzen, C.J. Elsevier, A. Dedieu, N. Veldman, A.L. Spek, Organometallics 22 (2003) 722;

(h) B.M. Trost, G.J. Tanoury, J. Am. Chem. Soc. 109 (1987) 4753; (i) B.M. Trost, G.J. Tanoury, J. Am. Chem. Soc. 110 (1988) 1636;

(j) B.M. Trost, M.K. Trost, J. Am. Chem. Soc. 113 (1991) 1850;

(k) B.M. Trost, S.K. Hashmi, J. Am. Chem. Soc. 116 (1994) 2183;

(l) H. Suzuki, K. Itoh, Y. Ishii, K. Simon, J.A. Ibers, J. Am. Chem. Soc. 98 (1976) 8494;

(m) C.M. Crawforth, I.J.S. Fairlamb, A.R. Kapdi, J.L. Serrano, R.J.K. Taylor, G. Sanchez, Adv. Synth. Cat. 348 (2006) 406;

(n) J.L. Serrano, I.J.S. Fairlamb, G. Sanchez, L. Garcia, J. Perez, J. Vives, G. Lopez, C.M. Crawforth, R.J.K. Taylor, Eur. J. Inorg. Chem. 13 (2004) 2706;

(o) K. Moseley, P.M. Maitlis, J. Chem. Soc., Dalton Trans. (1974) 109.

[2] A. Holuigue, C. Sirlin, M. Pfeffer, K. Goubitz, J. Fraanje, C. Elsevier, J. Inorg. Chim. Acta 359 (2006) 1773.

[3] (a) L. Canovese, F. Visentin, G. Chessa, P. Uguagliati, C. Levi, A. Dolmella, Organometallics 24 (2005) 5537;

(b) L. Canovese, F. Visentin, G. Chessa, C. Santo, C. Levi, P. Uguagliati, Inorg. Chem. Com. 9 (2006) 388;

(c) L. Canovese, F. Visentin, G. Chessa, P. Uguagliati, C. Levi, A. Dolmella, G. Bandoli, Organometallics 25 (2006) 5355.

[4] L. Canovese, F. Visentin, P. Uguagliati, B. Crociani, J. Chem. Soc., Dalton Trans. (1996) 1921.

[5] (a) L. Canovese, F. Visentin, G. Chessa, P. Uguagliati, A. Dolmella, J. Organomet. Chem. 601 (2000) 1;

(b) L. Canovese, F. Visentin, G. Chessa, G. Gardenal, P. Uguagliati, J. Organomet. Chem. 62 (2001) 155;

(c) L. Canovese, F. Visentin, G. Chessa, C. Santo, P. Uguagliati, L. Maini, M. Polito, J. Chem. Soc., Dalton Trans. (2002) 3696;

(d) L. Canovese, F. Visentin, P. Uguagliati, G. Chessa, Coord. Chem. Rev. 248 (2004) 945.

[6] In the case of the complex $\mathbf{2 B c}, k_{2}$ was determined by the method of initial rates by taking advantage of the simple structure of the time dependent complex concentration which can be expressed by the equation $-\mathrm{d}[\mathbf{2} \mathbf{B c}]=k_{2}[\mathbf{2 B c}][\mathbf{1} \mathbf{a}] \mathrm{dt}$. From the slope of the straight line obtained from the plot of [2Bc] vs time from NMR determinations at early reaction times one can obtain the second order rate constant $k_{2} \approx \operatorname{slope} /[\mathbf{2} \mathbf{B c}]_{0}[\mathbf{1 a}]_{0}\left([\mathbf{2 B c}]_{0}=3.6 \times 10^{-2},[\mathbf{1} \mathbf{a}]_{0}=8.3 \times 10^{-2} \mathrm{~mol} \mathrm{dm}^{-3}\right)$.

[7] (a) K. Harano, M. Yasuda, K. Kanematsu, J. Org. Chem. 47 (1982) 3736 ;

(b) M. Eto, T. Aoki, K. Harano, Tetrahedron 50 (1994) 13395;

(c) M. Matsuda, H. Matsubara, M. Sato, S. Okamoto, K. Yamamoto, Chem. Lett. (1996) 157.

[8] S. Saito, Y. Yamamoto, Chem. Rev. 100 (2000) 2901.

[9] Y. Yamamoto, A. Nagata, K. Itoh, Tetrahedron Lett. 40 (1999) 5035 .

[10] Y. Yamamoto, A. Nagata, Y. Arikawa, K. Tatsumi, K. Itoh, Organometallics 19 (2000) 2403.

[11] (a) Z. Zhou, L.P. Battaglia, G.P. Chiusoli, M. Costa, M. Nardelli, C. Pelizzi, G. Predieri, J. Chem. Soc. Chem. Commun. (1990) 1632

(b) Z. Zhou, M. Costa, G.P. Chiusoli, J. Chem. Soc., Perkin Trans. (1992) 1399;

(c) Z. Zhou, M. Costa, G.P. Chiusoli, J. Chem. Soc., Perkin Trans. (1992) 1407.

[12] K. Mizuno, K. Terasaka, N. Ikeda, Y. Otsuji, Tetrahedron Lett. 26 (1985) 5819. 